\title{
Congenital hepatic fibrosis and adult-type autosomal dominant polycystic kidney disease in a child
}

\author{
F.I. Lee and A.R. Paes* \\ Department of Gastroenterology, Victoria Hospital, Blackpool, Lancs FY3 8NR, UK.
}

\begin{abstract}
Summary: This reports a family with congenital hepatic fibrosis and adult polycystic kidney disease. Adult polycystic kidney disease was present in three generations. In addition, congenital hepatic fibrosis occurred in two members of the third generation. These conditions are generally held to have different modes of inheritance and the significance of their occurrence together is not clear.
\end{abstract}

\section{Introduction}

Congenital hepatic fibrosis (CHF) has been described in association with a variety of renal malformations. Well documented reports of CHF with adult-type autosomal dominant polycystic kidney disease (APCKD) are few. We report this combination in a child in whom there is a positive family history of APCKD.

\section{Case report}

The proband is a previously healthy 7 year old girl who was found to have an enlarged, firm liver at a routine medical examination. There were no stigmata of chronic liver disease. Routine haematological and biochemical tests, including serum bilirubin, aspartate transaminase and alkaline phosphatase, were normal. A wedge biopsy of the liver was taken at laparotomy. Histological examination showed normal lobular architecture but the portal tracts were enlarged by fibrosis with an excess of moderately dilated bile ducts (Figure 1). Appearances were typical of CHF. Barium swallow examination showed no oesophageal varices. Intravenous urography showed large rounded cysts with stretching and distortion of the calyces. The size and asymmetry of the cysts were typical of APCKD.

Four months later, she had massive gastrointestinal bleeding and received 12 units of blood by transfusion. A percutaneous transplenic venogram showed extensive gastro-oesophageal varices. The splenic pulp pressure was $28 \mathrm{~mm} \mathrm{Hg}$. An emergency spleno-renal anastomosis was performed. She made an uneventful

Correspondence: F.I. Lee, M.B., F.R.C.P.

*Present address: Department of Radiology, Southampton General Hospital Southampton, UK.

Accepted: 28 November 1984

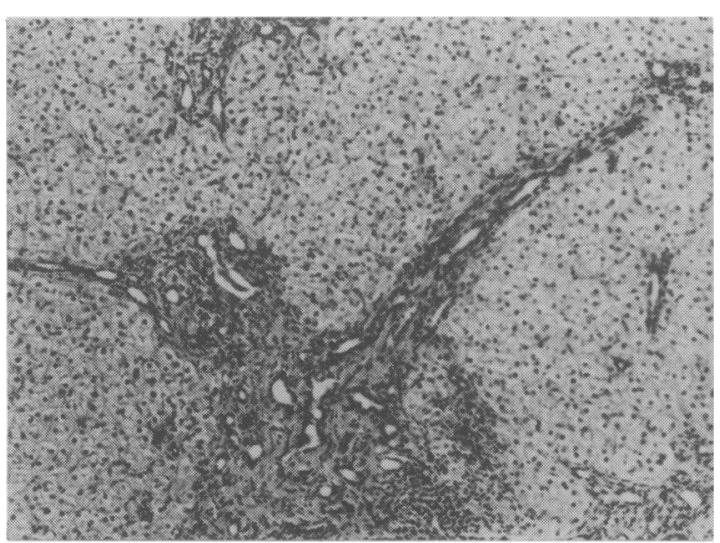

Figure 1 Wedge biopsy of liver taken at laparotomy. Normal lobular architecture, portal tracts enlarged by fibrosis with excess of moderately dilated bile ducts $(\mathrm{H} \& \mathrm{E} \times \mathbf{8 0})$.

recovery and remained well for $4 \mathrm{y}$. In 1978, when aged $11 \mathrm{y}$, she had a further gastrointestinal haemorrhage. An end-to-side porta-caval shunt was performed and she remained well for a further 4 months. At that stage a further haemorrhage was dealt with by multiple submucosal ligation of varices. Subsequently, she has remained well with normal physical development. When last seen, aged $17 \mathrm{y}$, in 1984 she felt well. She is of normal stature and intelligence. The liver and both kidneys are enlarged. The blood pressure is normal. Radiological examination has been limited in recent years but it is presumed that she has recurrent gastrooesophageal varices which will probably be dealt with by endoscopic sclerotherapy if further bleeding occurs.

Her father was referred to a medical outpatient 
clinic at the age of $39 \mathrm{y}$ for investigation and management of hypertension. The blood pressure was 170/ $100 \mathrm{~mm} \mathrm{Hg}$. Both kidneys were palpable. Serum creatinine was $153 \mu \mathrm{mol} / 1$ (upper limit of normal $125 \mu \mathrm{mol} / \mathrm{l})$. Intravenous urography showed evidence of typical APCKD with large cysts and distorted elongated calyces. Needle biopsy of the liver showed no abnormality and a barium swallow examination was normal with no visible varices. $\mathrm{He}$ has been followed up subsequently and blood pressure controlled with labetalol. In 1984, when aged $46 \mathrm{y}$, he felt well with a blood presure of $150 / 95 \mathrm{~mm} \mathrm{Hg}$. Biochemical examination showed no evidence of deterioration of renal function (blood urea $7.8 \mathrm{mmol} / \mathrm{l}$., creatinine $144 \mu \mathrm{mol} / 1$.).

The proband's sister was reviewed in 1982 at the age of $16 \mathrm{y}$. She is well with no abnormal physical signs. Intravenous urogram showed a duplex right kidney and a small left renal cyst.

The proband's 14 year old brother was reviewed in 1982. He had no complaints. He was known to have had a firm enlarged liver since he was aged $6 y$. On examination he had a palpable enlarged liver and spleen, presumed to be due to CHF. An intravenous urogram was normal at the age of $7 \mathrm{y}$. Ultrasound examination at age $13 \mathrm{y}$ confirmed hepatosplenomegaly and, in addition, a solitary cyst was visible in th left kidney. The child probably has CHF but not polycystic kidneys.

The proband's paternal grandmother died at the age of $51 \mathrm{y}$ and autopsy examination showed her to have polycystic kidneys (presumed APCKD).

\section{Discussion}

There is good evidence of APCKD in three generations of the family described in this report, confirming an autosomal dominant pattern of inheritance. In

\section{References}

BLYTH, H. \& OCKENDEN, B.G. (1971). Polycystic disease of kidneys and liver presenting in childhood. Journal of Medical Genetics, 8, 257.

DUPOND, J.L., MIGUET, J.P., CARBILLET, J.P., SAINTHILLIER, Y., PEROL, C. \& LE-CONTE-DE-FLORIS, R. (1978). Kidney polycystic disease in adult congenital hepatic fibrosis. Annals of Internal Medicine, 88, 514.

GAISFORD, W. \& BLOOR, K. (1968). Congenital polycystic disease of kidneys and liver, portal hypertension - portal anastomosis. Proceedings of the Royal Society of Medicine, 61, 304.

HOEFFEL, J.C., JACOTTIN, G. \& BOURGEOIS, J.M. (1970). A propos d'une famille associant des cas de polykystose fenale de type juvenile et de type adulte. Annals of Radiology, 14, 205.

KERR, D.N.S., HARRISON, C.V., SHERLOCK, S. \& MILNES addition one, certainly, and another, probably, of the three members of the third generation have CHF. This conforms with the autosomal recessive transmission normally attributed to this condition (Kerr et al., 1961). The significance of the occurrence of the two conditions together is uncertain but has been noted previously (Gaisford \& Bloor 1968; Hoeffel et al., 1970; Tazelaar et al., 1984).

In early reports of CHF, there was noted to be an association with childhood type autosomal recessive polcystic kidney disease in $33 \%$ of sporadic cases and $70 \%$ of familial cases (Sommerschild et al., 1973). Blyth \& Ockenden (1971) characterized four subgroups of renal involvement in CHF according to the percentage of tubules involved. All groups were compatible with autosomal recessive inheritance with a different mutant gene being responsible for each subgroup. It has been suggested that in some cases of apparent APCKD in association with CHF the renal lesion may be ectasia of the collecting tubules at an advanced stage (Dupond et al., 1978). Patients with infantile-type polycystic kidney disease may develop large cortical and medullary cysts resembling those found in APCKD (Lieberman et al., 1971) so a family history is crucial for a certain diagnosis of APCKD in association with CHF. Murray-Lyon et al., (1973) have drawn attention to the various combinations of hepatic and renal fibrocystic lesions and suggestec that CHF should not be regarded as a distinct entity.

The autosomal dominant gene of APCKD shows almost $100 \%$ penetrance. Due to the variability that is typical of autosomal dominant inheritance, APCKD may be present in childhood. This may cause confusion and a wrong diagnosis of childhood polycystic kidney disease may be made. However, pathologically and radiologically the two diseases are quite distinct and the diagnosis of APCKD is confirmed in the family reported here by the occurrence of polycystic kidneys in three generations.

WALKER, R. (1961). Congenital hepatic fibrosis. Quarterly Journal of Medicine, 117, 91.

LIEBERMAN, E., SALINAS-MADRICAL, L., GWINN, J.L., BRENNAN, L.P., FINE, R.N. \& LANDING, B.H. (1971) Infantile polycystic disease of the kidneys and liver. Medicine, 50, 277.

MURRAY-LYON, I.M., OCKENDEN, B.G. \& WILLIAMS, R. (1973). Congenital hepatic fibrosis - is it a single clinical entity? Gastroenterology, 64, 653.

SOMMERSCHILD, H.C., LANGMARK, F. \& MAURSETH, K. (1973). Congenital hepatic fibrosis: report of two new cases and review of the literature. Surgery, 73, 53.

TAZELARR, H.D., PAYNE, J.A. \& PATEL, N.S. (1984). Congenital hepatic fibrosis and asymptomatic familial adult-type polycystic kidney disease in a 19 year old woman. Gastroenterology, 86, 757. 